\title{
Assessment of Attitudes \\ Toward an Asynchronous Communication Tool \\ Used as a Required Part of the MBA Curriculum
}

\author{
Edward Weiss \& Alex Koohang \\ National-Louis University, USA
}

koohang@ceintertace.com

\begin{abstract}
Higher education institutions are increasingly embracing the Internet as a tool to support academic courses and/or programs. Little research has been done to assess students' attitudes toward the Web-based instructions and communication tools that supplement academic courses and/or programs. The purpose of this study was to assess students' attitudes toward the on-line asynchronous communication tool used as a required part of the MBA curriculum at a medium-sized university in the Midwest. The on-line asynchronous communication tool known as the MBA websupport/discussion forum is the nucleus of the interaction between students and faculty, and among students. It simulates the traditional classroom discussion activities among groups and between students and faculty. It also allows posing of course information, syllabi, office hours, and weekly assignments/activities. A Likert-type questionnaire consisting of 20 items was constructed and administered to 74 MBA students. The results of this study showed that respondents did not express high positive attitudes toward the on-line asynchronous communication tool. The discussion is focused on three elements that might be responsible for learners' attitudes toward on-line communication tool used to deliver Web-base courses or programs. These elements are on-line instructional design, building on-line community, and training. Recommendations are made based on the findings of this study.
\end{abstract}

Keywords: asynchronous communication, Web-based instruction, attitudes, MBA students

\section{Background}

The effect of attitudes toward new and emerging technologies is extensively acknowledged in the literature (Bandalos \& Benson, 1990; Dupagne \& Krendl, 1992; Loyd \& Gressard, 1984; \& Koohang 1989). In a metaanalysis of empirical studies regarding computers in educational settings, Kulik (1994) noted that students who received computer-based instruction in their classes tended to like their classes more, learn more, learn in less time, and develop more positive attitudes toward computers.

In another meta-analysis research in the area of applications of technology to education and training, Fletcher (1996) reported that technology was equally effective for both knowledge and performance outcomes. He also stated that the effectiveness of instruction, to a large ex-

Material published as part of this proceedings, either on-line or in print, is copyrighted by the author with permission granted to the publisher of Informing Science for this printing. Permission to make digital or paper copy of part or all of these works for personal or classroom use is granted without fee provided that the copies are not made or distributed for profit or commercial advantage AND that copies 1) bear this notice in full and 2) give the full citation on the first page. It is permissible to abstract these works so long as credit is given. To copy in all other cases or to republish or to post on a server or to redistribute to lists requires specific permission from the author. tent, relies on the introduction of technology. SAP research (1996) concluded that technology has positive effects on student attitudes toward learning. The study further explained that the academic skills were enhanced when on-line communications were used.

The Internet has become a significant tool that may enhance the learning process in educational settings. Rafaeli \& Ravid (1999) reported that the Internet Web-based online asynchronous discussion tools used to supplement an introductory business information systems course enhanced instructor-student and student-to-student interaction.

Robertson and Stanforth (1999) examined the interest of students in Web-based courses as well as their computer skills and attitudes. The study reported that students expressed positive attitudes. In another study on student perceptions of supplemental Web-based instruction, Angulo \& Michelle (1999) found that students perceived the supplemental Web-based instruction to be beneficial. The discussion forum was among the most liked features in the supplemental Web-based instruction. 


\section{Attitudes \& Asynchronous Communication}

Currently many colleges and universities are using the Internet as a tool to support academic courses and/or programs. IDC (1999) predicts that "the number of college students enrolled in distance-learning courses will reach 2.2 million in 2002".

Koohang (1989) stated that user acceptance is an essential factor in successful implementation of new technologies. The acceptance of technology can be influenced by the user attitudes thus positively effecting the learning process. The purpose of this study was to assess students' attitudes toward the on-line asynchronous communication tool used as a required part of the MBA curriculum at a mediumsized university in the Midwest.

Because of its accelerated nature, the Web-based MBA at this university requires that students meet one night per week. The completion of the program takes less than two years. To insure the quality of the program, the Websupport/discussion forum is used as a required part of the MBA program. In addition to one night per week face-toface meeting, students are required to carry out their assignments, activities, and discussion on to the MBA Websupport/discussion forum a minimum of three times a week.

This on-line asynchronous communication tool known as the MBA Web-support/discussion forum is the nucleus of the interaction between students and faculty, and among students. It simulates the traditional classroom discussion activities among groups and between students and faculty. The asynchronous communication tool also allows instructors to post their course information, syllabi, office hours, and weekly assignments/activities.

As the Internet increasingly being used to enhance learning within the academic settings, it is imperative to assess students' attitudes toward the Web-based instructions and communication tools that supplement academic courses and/or programs.

\section{Method}

\section{Instrumentation}

A Likert-type questionnaire consisting of 20 items was constructed to assess attitudes toward an on-line asynchronous communication tool that was used as a required part of the MBA curriculum at a medium-sized university in the Midwest. A panel of five professors who taught in both the MBA and IT programs determined the content validity of this questionnaire. The items present positively worded statements such as "The MBA Web Support/Discussion Forum is an effective supplemental learning tool" and "I believe the interaction among students on the MBA Web Support/Discussion Forum contribute to the learning proc-

1. The MBA Web support is an effective supplemental learning tool.

2. I am motivated every time I use the MBA Web support to do the assignments.

3. I believe the interaction among students on the MBA Web support contribute to the learning process.

4. The MBA Web support is an important part of the learning process.

5. My time is well spent using the MBA Web support.

6. I think the MBA Web support is a valuable part of the curriculum.

7. The activities in the MBA Web support are useful and contribute to the learning process.

8. I feel that I gain a lot from the MBA Web support.

9. I believe the MBA Web support is user-friendly.

10. It is fun using the MBA Web support.

11. The students/professor interactions on the MBA Web support contribute to the learning process.

12. It is worthwhile using the MBA Web support.

13. I feel more involved using the MBA Web support.

14. The use of MBA Web support helps me learn more.

15. I believe the MBA Web support enhances the learning process.

16. I enjoy increased communication with instructors and fellow students using the Web support.

17. I feel that I learn how to support arguments by participating in the Web support.

18. I feel that I have refined my analysis and problem-solving skills by participating in the Web support.

19. I believe I have developed myself as a team member by participating in the Web support.

20. I believe that conversation on the Web support/Discussion Forum was as valuable as inclass conversations.

Table 1. Questionnaire Items 
ess". The responses to the items were recorded so that strongly agree $=5$, agree $=4$, neither agree nor disagree $=3$, disagree $=2$, and strongly disagree $=1$. A higher score indicated a higher positive attitude. The items are shown in Table 1.

The internal consistency of this questionnaire was determined using 47 students who were enrolled in an MBA program. The sample used to determine internal consistency was independent of the sample of respondents used in the study itself. The calculated coefficient alpha reliability from the results for this instrument was .93. This result suggests that the instrument is stable enough to assess attitudes toward the on-line asynchronous communication tool used as a required part of the MBA curriculum.

\section{Sample \& Procedure}

The questionnaire was administered on-site to 81 students who were enrolled in the MBA program at a medium-sized university in the Midwest, USA. Seven questionnaires were eliminated because of missing data yielding a final sample of 74. The respondents were given rationale for their participation, and they were assured that their responses would be anonymous and confidential. Table 2

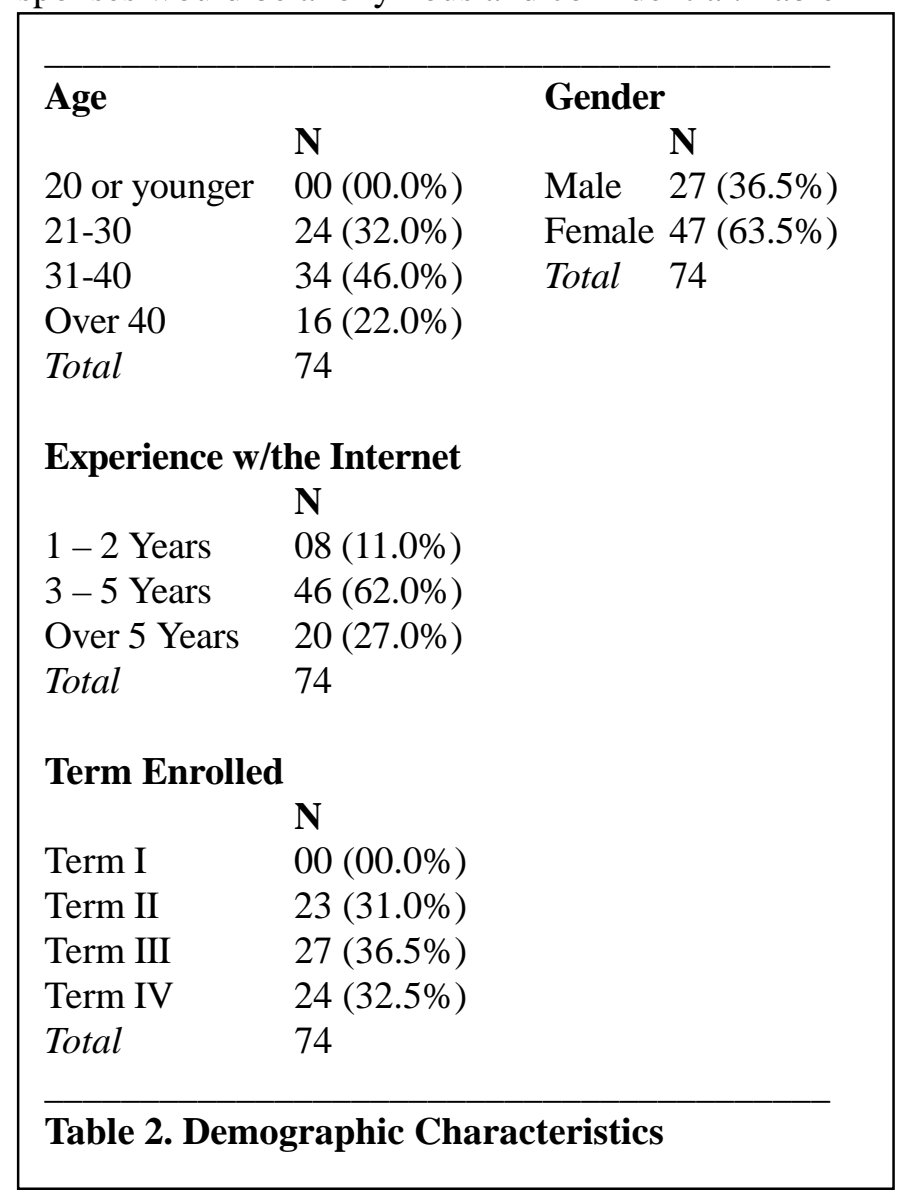

shows the demographic characteristics of the respondents.

\section{Results}

Table 3 shows the summary of descriptive analyses for the 20 items on the questionnaire. All of the items were statistically above the midpoint scale, i.e., maximum possible score $=5.0$ and midpoint $=3.0$. However, no item on the questionnaire yielded a high positive attitude, i. e; a score equal to 4 or 5 . In general, the respondents expressed neutral attitudes toward the on-line asynchronous communication tool used as a required part of the MBA curriculum.

\section{Discussion}

This study showed that overall the respondents expressed neutral attitudes toward the on-line asynchronous communication tool used as a required part of the MBA curriculum. It is noteworthy to mention that respondents did not express high positive attitudes toward the on-line asynchronous communication tool used as a required part of the MBA curriculum. The on-line asynchronous communication tool is a powerful tool that has a very simple and understandable user interface. Because of its extremely useful characteristics that can lead to user

\begin{tabular}{|lccccc|}
\hline Item & N & Min & Max & Mean & SD \\
\hline$\# 1$ & 74 & 1.00 & 5.00 & 3.6486 & 1.1400 \\
$\# 2$ & 74 & 1.00 & 5.00 & 3.2162 & 1.1736 \\
$\# 3$ & 74 & 1.00 & 5.00 & 3.7838 & 1.0761 \\
$\# 4$ & 74 & 1.00 & 5.00 & 3.5811 & 1.1227 \\
$\# 5$ & 74 & 1.00 & 5.00 & 3.3514 & 1.0654 \\
$\# 6$ & 74 & 1.00 & 5.00 & 3.4054 & 1.2041 \\
$\# 7$ & 74 & 1.00 & 5.00 & 3.5000 & 1.1257 \\
$\# 8$ & 74 & 1.00 & 5.00 & 3.2297 & 1.1048 \\
$\# 9$ & 74 & 1.00 & 5.00 & 3.6486 & 1.2434 \\
$\# 10$ & 74 & 1.00 & 5.00 & 3.1081 & 1.1295 \\
$\# 11$ & 74 & 1.00 & 5.00 & 3.3919 & 1.1565 \\
$\# 12$ & 74 & 1.00 & 5.00 & 3.4054 & 1.1927 \\
$\# 13$ & 74 & 1.00 & 5.00 & 3.3378 & 1.2194 \\
$\# 14$ & 74 & 1.00 & 5.00 & 3.2973 & 1.0946 \\
$\# 15$ & 74 & 1.00 & 5.00 & 3.4324 & 1.1596 \\
$\# 16$ & 74 & 1.00 & 5.00 & 3.3649 & 1.1536 \\
$\# 17$ & 74 & 1.00 & 5.00 & 3.1486 & 1.2014 \\
$\# 18$ & 74 & 1.00 & 5.00 & 3.1622 & 1.1939 \\
$\# 19$ & 74 & 1.00 & 5.00 & 3.3649 & 1.2668 \\
$\# 20$ & 74 & 1.00 & 5.00 & 3.1757 & 1.3175 \\
& & & & & \\
\hline Table 3. Descriptive Statistics & \\
\hline
\end{tabular}




\section{Attitudes \& Asynchronous Communication}

acceptance of the technology, one might assume that respondents would have expressed higher positive attitudes toward the asynchronous communication tool. However, this study did not yield that result and thus it is important to mention that the useful characteristics of this on-line communication tool are not merely sufficient to increase positive attitudes.

In making judgment about the Web-bases delivery format and its relation to learners' attitudes, focus must be on the initial consideration to the balance among the following: 1) on-line Web-based instructional design, 2) building on-line community, and 3) training.

Unfortunately many colleges and universities take part in Web-based courses and programs without paying much attention to the above elements. Based on our observations and experience with Web-based design, development, implementation and delivery, we believe that these elements are imperative. They can positively effect learners' attitudes thus influencing the learning process. In the next segment we will further discuss these elements.

\section{On-line Web-based Instructional Design}

The on-line Web-based program design is highly collaborative. The faculty should maintain responsibility for curriculum design and content in their disciplines or fields (Durante, Koohang, Weiss, 2000). To assure integrity of on-line Web-based delivery, faculty should be held responsible for the management and coordination of their on-line activities. The move from a traditional face-toface system of education to on-line Web-based education creates tremendous transitional demands on faculty and students. While distance education programs may significantly improve access to a variety of college offerings, the implementation of these programs require teachers and learners to approach and carryout their objectives in entirely new and creative ways. This requires that faculty be knowledgeable and possess expertise in instructional design.

The Web-based design instruction can draw on a scope of learning theories and goal orientations, styles of collaboration, and teacher support that meet the need for flexible learning environments (Chisholm and Wetzel, 1997; Reeves and Reeves, 1997).

When these elements are taken into consideration for designing Web-based instruction and communication tool, they may effect the learners' attitudes and therefore contribute a great deal to their learning.

\section{Building On-line Community}

The task in successful development of new on-line activities is based on communication (Seymour, Durante, Koohang, 1999). It is therefore, assumed that setting expectations and meeting them early on and consistently communicating these expectation to the learner will allow the on-line Web-based program to move forward productively with effort spent on teaching and learning. In general, the on-line Web-based course tends to rely heavily on language and the way it is communicated. Through communication on-line community is built. Building online community early on may contribute to students' positive attitudes thus influencing their learning process.

\section{Training}

Appropriate training of the faculty to teach on-line Webbased courses may influence students' learning process thus positively influencing students' attitudes. If proper and appropriate training is not provided for the faculty who teaches on-line, the entire process of on-line Web-based education may fail. Faculty needs specific skills in order to implement his/her plans to teach on-line. There is always some faculty members who will lead the way on their own, but most definitely need training to get started with on-line Web-based courses. There must be a dedicated team of technical people assigned to assist the faculty when they needed help. For a successful on-line Webbased program, faculty training must occur constantly. Professional development funds should be set aside to support beginner faculty and enhance the development of more experienced (Seymour, Durante, \& Koohang, 1999). Needless to say that appropriate training must also be provided for students learning on-line.

\section{Conclusion}

The Web-based courses and programs are becoming increasing popular in the academic settings. The learners' positive attitude is imperative in successful implementation and delivery of Web-based courses and programs. The implementation of Web-based courses and programs require new and creative approaches with considerable research and development. A sound communication tool/courseware offers only partial solutions to a fine online Web-based delivery system. The change from a traditional face-to-face method of instructional delivery and 
communications to the one that has a promising future requires constant assessment, evaluations, and sound management and control. An effective solution requires attention to instructional design, building on-line community, and training. These elements are critical and imperative in successful implementation of Web-based courses and programs. These elements may contribute positively to learners' attitudes thus influencing the learning process. Therefore, these elements must be given careful attention in designing and delivering Web-based courses and programs and be included in further research.

\section{References}

Angulo, A \& Bruce, M (1999). Student Perceptions of Supplemental Web-Based Instruction. Innovative Higher Education, 24(2). p105-25.

Bandalos, D., \& Benson, J. (1990). Testing the factor structure invariance of a computer attitude scale over two grouping conditions. Educational and Psychological Measurement, 50(1), 49-60.

Chisholm I M and Wetzel K (1997) Lessons learnt from a technology integrated curriculum for multicultural classrooms. Journal of Technology and Teacher Education 5(4) 293-317.

Dupagne, M., \& Krendl, K. A. (1992). Teachers' attitudes toward computers: A review of the literature. Journal of Research on Computing in Education, 24 (3), 420-429.

Durante, A., Koohang, A., \& Weiss, E. (2000). Teaching and learning on-line: Lessons learned. Proceedings of World Association for Case Method Research \& Application.

Fletcher, J. D. (1996). Does this Stuff Work? Some Findings from Applications of technology to Education and training. Proceedings of Conference on Teacher Education and the Use of Technology Based Learning Systems. Warrenton VA: Society for Applied Learning.

International Data Corporation (IDC) (1999). IDC's Online Distance Learning in Higher Education, 1998-2002, [Online], Available: nttp://www.idc.com
Koohang A. (1989). A Study of Attitudes Toward Computers: Anxiety, Confidence, Liking, and Perception of Usefulness. Journal of Research on Computing in Education. 22(2). 137-150.

Kulik, A. J. (1994). Meta- Analytic Studies of finding on Computer Based Instruction. In E. L. Baker \& H. F. O'Neil (eds.),Technology Assessment in Education and Training. Hillsdale, NJ: Lawrence, Erlbaum.

Loyd, B. H., \& Gressard, C. (1984). The effects of sex, age, and computer experience on computer attitudes. Association for Educational Data Systems, 18(2), 67-77.

Rafaeli S., \& Ravid G. (1997). On-line, Web Based Learning Environment for an Information Systems Course: Access logs, Linearity and Performance. ISECON '97.

Reeves T., \& Reeves P. (1997) Effective dimensions of interactive learning on the World Wide Web in Khan B (ed) Web-based Instruction Educational Technology Publications, Englewood Cliffs, NJ, 59-66.

Robertson and Stanforth (1999). College students' computer attitudes and interest in Web based distance education. Journal of Family and Consumer Sciences. 91(3), 60-64.

Seymour, T., Durante, A., \& Koohang, A. (1999). "Developing Distance Education Programs/Courses for Web-based Delivery." A Collection of Papers on Institutional Improvements. North Central Association, Chicago.

Software Publishers Association (SPA) (1996) Report of the Effectiveness of Technology in Schools, 95-96, [Online]. Available: http://www.spa.org/project/edu_pub/summary.htm

\section{Biographies}

Edward Weiss is a professor and director of the MBA program in the College of Management \& Business at National-Louis University, Chicago, Illinois. His current research interest is distance and Web-based education.

Alex Koohang is a professor and director of the Masters in Electronic Commerce in the College of Management \& Business at National-Louis University, Chicago, Illinois. His current research interest is distance education and electronic commerce. 